experiments of an exploratory nature on the flow of linoleum compositions, an extrusion technique was evolved. Calendering, of course, can in many respects be considered as two-dimensional extrusion. It is possible with such an apparatus to work with pressures which are of approximately the same order of magnitude as those in use on an actual calender. The extrusion apparatus described can be used with a series of nine extrusion nozzles (three different lengths, each of three different diameters) in order to measure end effects, or with one nozzle for routine testing. Mr. Ward discussed the significance of the results he has obtained in relation to the manufacture of linoleum, particularly with respect to the effects of combined hydrostatic pressure and shearing stress as in the calendering process.

An extrusion apparatus, which has been developed from the prototype outlined by Mr. Ward, was described by Messrs. F. T. Walker and J. Arnot (Michael Nairn and Co., Ltd.). By extruding unseasoned linoleum in this apparatus, the behaviour under calendering conditions and the effect exerted by the various conventional fillers can be demonstrated. The relationship between temperature and extrusion-rate at constant pressure, for linoleum mixes containing known volumes of fillers, was shown in a series of curves. A constant factor appears to exist between the equivalent amounts of any two fillers which have the same effect on flow. Apart from sheet formation, marble and other decorative effects are dependent on the flow characteristics of the unseasoned mix. A few curves of related floorcoverings, for example, asphalt tile and polyvinylchloride flooring, were given. The problem of solidliquid mixtures was examined by Mr. P. Rigden (Road Research Laboratory, Harmondsworth). $\mathrm{He}$ quoted information derived from filler-binder systems as used in the road-building industry and showed how the analysis of rheological data gives information of the structure and make-up of the particular system. In a practical paper describing the use of a penetrometer-type instrument to measure the deformation of unmatured linoleum, Mr. C. W. Falkner (Linoleum Manufacturing Co.) gave some interesting facts correlating results obtained on this instrument with composition of the sample under test. An attempt has been made to study quantitatively the flow properties of the linoleum plastic mix, with special reference to changes in workability and plasticity with temperature.

A method of evaluation of the rheological properties of linoleum composition was described by Messrs. G. D. Rack and F. J. Rigby (Jas. Williamson and Son, Ltd.), which is based on a creep-curve method, one that needs only the simplest of apparatus. In practice, samples of linoleum composition after calendering are cut into strips of standard length and the rate of extension measured with different applied stresses. Experimental work shows the effect of mixing-time on linoleum compositions containing all cork (or wood flour) as the cellular filler, the effect of the type of filler and the effect of the age of the sheet. Although there are certain limiting factors to the use of this technique, the method needs no expensive apparatus and is within the reach of all investigators. Mr. R. W. Whorlow (Research Association of British Rubber Manufacturers) de. scribed the relative merits of various types of instruments used for the measurement of plasticity in the rubber industry and, in particular, discussed the merits of the rotational instruments used, which in some cases had been deprecated during the discussion at the symposium. The methods of using these various instruments and possible ways of modifying them to be of use to the linoleum industry were dealt with.

In summing up, Mr. Ward said that certain points stand out very clearly; one of them, the measurement of composition on a volume basis, is a fruitful approach. He suggested that by making a start with the binder in the composition and by studying its properties in detail, in a similar way to the work which has been carried out at the Road Research Laboratory, some important and interesting data could be obtained. Mr. Ward was of the opinion that, although the extrusion type of apparatus is particularly useful, there may be a limit to its usefulness, and it is not easy to separate certain effects. The theory of calendering was discussed at the symposium, and this is tied in many ways to extrusion; but he suggested that the industry should also consider other fields, that is, in the early stages of manufacture, as calendering is not the only process used in making linoleum.

\section{QUANTITATIVE ECOLOGY OF PLANKTON}

$T$

HE population of plankton organisms in the sea is composed of plants and animals of very assorted sizes and shapes. Of these, the microscopic plants are producers, and the smaller animals are consumers-but also producers of fish-life. The productivity of the sea is dependent upon a complex of physical and chemical conditions, chief among which are the radiation of the sun and nutrient substances containing phosphorus and nitrogen.

Our knowledge of this many-sided picture is now sufficiently detailed to allow attempts at mathematical treatment. The accumulation of the necessary data has taken many years of painstaking and sustained research in many directions, much of which has needed the elaboration of special methods. By this means quantitative knowledge has been obtained on the seasonal and regional changes in amounts of nutrient salts, the penetration of the sun's radiation into the sea, and the conditions leading to stability or unstability of the water column and hence the turbulence.

The collection of the information on the living populations, although it was started earlier, has been slower and less organised, largely owing to the varied interests of the research workers. First, the constituent members of the flora and fauna had to be de. scribed and identified; studies of their comparative abundance and seasonal and regional distribution were ends in themselves, as were their life-histories. But when sufficient was known, attempts were soon made to correlate the seasonal and other changes in the populations with the physical and chemical conditions. In general, these correlations have been expressed in numbers of different individuals of the population. Perhaps this was rather natural, since estimations were chiefly made by botanists and zoologists who had interests in the organisms as such. But a correct assessment of the overall production can only be made by chemical means. Information on photosynthesis, respiration, and metabolism of plankton plants and animals has been obtained by experiment. Assessment of quantity of plant life in 
unit volumes of sea-water has been made by estima tion of the amount of plant pigment, and data on volumes, dry weight and composition of representative plankton animals have been obtained.

By the use of reasonable average-constants for all the factors concerned in an evaluation of the dynamics of a plankton population, G. A. Riley showed that it was possible to produce equations which gave promise that theoretical treatment might provide an understanding of the fundamental processes controlling plankton "growth and distribution. In subsequent work he found that with selected seasonal data from different regions the changing abundance of the population could be predicted with a fair degree of approximation using theoretical equations. His latest collaboration, with $H$. Stommel and D. F. Bumpus $^{1}$, is an attempt to examine the principles of regional distribution.

This work and its predecessors deserve close attention by ecologists. They emphasize gaps in our knowledge, and perhaps impress upon us most the need to come to agreement on the best methods of quantitative assessment of the varying populations. The fact that the synthesis of the picture has advanced so far that it is amenable to mathematical expression should in itself act as a stimulus for renewed efforts.

F. S. RUussell

Riley, G. A., Stommel, H., and Bumpus, D. F. "iQuantitative Ecolog Oceanogr. Collection, 12, - rt. 3,1 (1949).

\section{IMPERIAL COLLEGE OF SCIENCE AND TECHNOLOGY}

\section{ANNUAL REPORT}

T

HE forty-second annual report of the governing body of the Imperial College of Science and Technology* covers the year ended July 31, 1949, and, besides the statement of accounts, contains a list of publications during the year, arranged by departments, and a list of changes in the teaching and administrative staff. The number of full-time students during the year was 1,428 , as against 1,510 in 1947-48, and of these 87 came from foreign countries, 140 from the Commonwealth overseas and 406 from the British Isles outside a radius of thirty miles from the College. The total of academic distinctions for 1948-49 was 800 as compared with 875 in $1947-48,700$ in $1946-47$ and 618 in 1939-40.

Among important educational developments noted in the report are the offer by the trustees of the Rockefeller Foundation of $£ 27,200$ to cover the cost during 1949-52 of a research fellow in public health engineering at the College and a tutor at the London School of Hygiene and Tropical Medicine. Standard Telephones and Cables, Ltd., has contributed $£ 1,200$ per annum for seven years towards the establishment of the Henry Mark Pease readership in telecommunications, while the University Grants Committee has financed the further development of geometrical optics in the Technical Optics Section of the Physics Department. Proposals for research work and training at a high level in mineral dressing are being implemented through a recurrent grant of $£ 6,500$ per annum from the University Grants Committee, and application has been made for a capital grant for the

* Forty-second Annual Report of the Governing Body of the Imperial College of Science and Technology Pp. 53. (London : reorganisation and modernization of the Bessemer Laboratory for this purpose.

The report also refers to the revision of building plans with the idea of allocating the ground now available to the more urgently needed buildings : plans for a new aeronautics building, an extension of the Unwin building and a further extension of the chemical technology building have already been submitted. Completion of these immediate projects will also provide for an extension of the Biological Departments. As a first step towards the encouragement of cultural studies and giving students the opportunity of preparing themselves also for life in its broader aspect, a course of lectures on "Ends and Means in Science" has been arranged, to be given by professors of the College to members of the College as a whole.

\section{FOREST POLICY IN UGANDA} ANNUAL REPORT FOR 1948

$\mathrm{D}$ URING 1948 the turning point in forestry seems to have been made in Uganda. The report for the year* commences with the following paragraph : "Russia continues to have a series of five-year plans. In Uganda we have a general development ten-year plan. Now His Excellency the Governor has pro. duced a plan for centuries - a statement on Forest Policy. For the first time since the Forest Department was formed they have been given a real directive." Of course, these things have been said before, but it would appear that Uganda, through its Governor, has envisaged a real forest policy. Briefly the points are : "(1) To reserve in perpetuity, for the benefit of the present inhabitants of Uganda and of posterity, sufficient land (either already forested or capable of afforestation) to maintain climatic conditions suitable for agriculture, to preserve water supplies, to provide forest produce for agricultural, industrial and domestic purposes, and to maintain soil stability in areas where the land is liable to deterioration if put to other uses. (2) To manage the forest estate to obtain the best financial returns on its capital value and the expenses of management, in so far as such returns are consistent with the primary aims set out above. (3) To foster, by education and propaganda, a real understanding among the people of Uganda of the value of forests to them and their descendants. (4) To encourage and assist the practice of sound forestry by Local Authorities and private enterprise; and to educate selected Africans in technical forestry."

The work describod in this report gives confidence that a start has been made with putting into force this suggested forest policy, and it is to be hoped that the effort will be maintained. So often in the past these suggestions of forest policy have been announced, only to be entirely ignored by subsequent governors and their councils, usually on the score that the Colony is in financial difficulties, and therefore the forest policy is one of the first things to suffer. Moreover, no announcement of a new forest policy, and even its introduction by the governor concerned, is of any use unless the strength of the forest department is sufficient to carry out the plan. In the past this has certainly not been the case with the forest departments in East Africa. * Uganda Protectorate. Annual Report of the Forest Department Government Printer, 1949.) 28. 